\title{
Editorial
}

\section{Where were you when YouTube was born?}

\author{
Journal of Brand Management (2007) 14, 207-210. doi:10.1057/palgrave.bm.2550069
}

\section{THE REVOLUTION CONTINUES}

Cast your mind back a little: $10-15$ years ago, say. Before the Second Iraq War. Before September 11th or the Tsunami in the Maldives. Before Diana died and YouTube was born. Brand management was so much easier then, wasn't it? You knew exactly where you stood. Brandbuilding budgets virtually allocated themselves, spread strategically across the restricted range of available media. TV would feature if the brand was big enough. Then there would be plenty of press ads. A few radio spots. A poster campaign or two. A dash of DM, perhaps. Some instore displays. T-shirts for the sales force to wear at exhibitions. Ah, those were the days.

But it's all so different now. Our world has changed dramatically over the past few years-perhaps largely because communications have become instant and international in ways that only science fiction aficionados might have anticipated. Just cast your eyes over this edition of the Journal of Brand Management and you'll see few topics that would have been discussed as recently as ten years ago. And as the World Wide Web, e-mail and mobile devices have stretched their communications cobweb into more and more households, consumer choices have also grown exponentially.

These relatively recent developments have made brand management today considerably more challenging than it was during the half-century or so since May 13, 1931-the day on which Neil McElroy of P\&G changed marketing forever by writing the classic memo that led to the creation of the discipline of brand management. ${ }^{1}$ Today's brand management challenge, in our global post-modern marketplace, is getting the spread right. Exactly where should you splash the cash?

\section{MAY YOU LIVE IN INTERESTING TIMES}

Although it's not clear whether the phrase 'may you live in interesting times' really is an ancient Chinese curse, ${ }^{2}$ these are certainly interesting times in which to be involved with brand management.

Today's global communications make it possible to showcase a brand to the world in general, but also, paradoxically, to precisely selected individuals. You can now, virtually (in both senses of the word) shake hands with each of your potential customers, delivering a personalised message that is tailored to say exactly what you believe they want to hear. This may seem like a good thing, but of course there is a danger of it all becoming too complex and confusing, for both consumers and brand management professionals alike. Information overload is growing as rapidly as the methods of information delivery. It's becoming apparent that too much choice may be as bad as too little, because consumers are now reacting adversely to the relentless bombardment by filtering out more and more of the information they are confronted with. Focusing on what's important is an inherent ability mankind has had since the caveman days, so just as most of us now notice only the road furniture we are specifically looking for, such as direction signs and speed cameras, we now also tend to notice only 
the brand messages we are specifically interested in. So what's the solution?

\section{THINK ABOUT IT}

I believe that now, 75 years after the birth of brand management, is a good time for everyone involved in this complex field to throw away the rulebook and think again. It's time to start with a blank sheet of paper, in effect, by carefully evaluating each individual medium (or sub-medium) as if you were considering it for the first time.

In fact, with many of the latest mediums, you really are considering them for the first time. Or perhaps you're not considering them at all? How much do you truly know about Viral Marketing (which is growing even faster since the advent of websites such as YouTube and MySpace); Podcasts; Blogs; RSS (Really Simple Syndication); Mobile Television; Online Magazines; Virtual Communities? All of these and many other emerging media can make a case for a place in your branding vocabulary. And which of the original, 'old-fashioned', ones should you continue deploying in this wired-and increasingly wireless-world? Where now are the best places to 'big-up' a brand? On the consumer's breakfast table, in their newspaper or in their 'snail mail' post? On the radio in the bathroom or the car? On the platform at the station or in a podcast on their MP3 player? On their television, computer or cinema screen? Via a message in their e-mail or a pop-up on their web browser? In their face (and their hands) at the point of purchase?

Naturally, the choices will depend on a vast range of factors: the product or service involved; the budget; the customer profile; the research findings; the knowledge of the marketing team and especially on the ability and inclination of the planning department to explore the everexpanding variety of options-because the more options there are, the more difficult and time-consuming it is to understand and exploit them.

But in order to accommodate all of these new media-many of which are undoubtedly valid, and valuable, additions to the marketing mix-I think we need to take a step back before we can confidently go forward. To understand the bigger picture, we need to first understand where the traditional vehicles-one of which is merchandising, my speciality-fit in. No doubt experts on the other traditional channels such as television, the press, or radio (and on the many emerging media and sub-media) will step forward to enlighten us about their particular areas of interest-and that will be positive, because we can all benefit from taking a closer look at the variety of available options. Only by knowing and understanding all of the options can brand professionals make informed decisions about which media should be used in which proportions to maximise the impact and cost-effectiveness of the overall offer package.

So, at the risk of appearing biased, which I am, I will explain some of the many reasons why merchandising is a major-and growing - part of the marketing mix, playing a key role as a strong foundation element in virtually every brand management programme.

\section{POP-THE FINAL LINK IN THE MARKETING CHAIN}

It's clear that above-the-line advertising is still declining, as media fragmentation increases.P\&G,for example, have announced their intention to reduce advertising on television from $90+$ per cent of marketing spend to 80 per cent or below. 


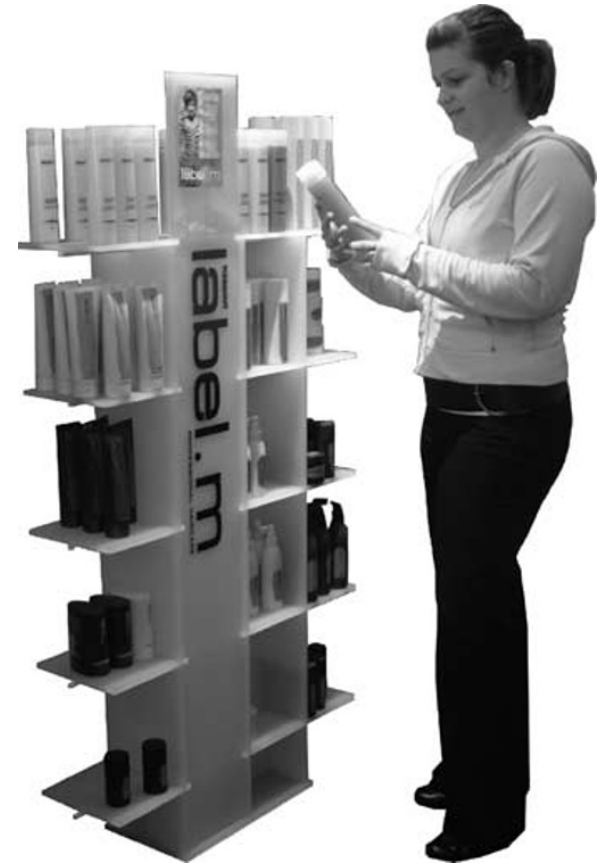

Although much of the liberated abovethe-line expenditure is finding its way into new media, one of the traditional below-the-line channels-Point of Purchase (POP) - has also grown enormously in importance to brands in the last few years. This is because POP merchandising is a simple, straightforward means of bringing brands and their potential purchasers much closer together-particularly now, in a world of increasing globalisation. POP display is perfect for brand communication across international boundaries, free from language barriers because it creates an immediate visual awareness whether seen in Stockholm, Shanghai or Sydney, and relating to virtually any product or service-from lingerie or cosmetics to insurance leaflets or books.

Despite the growth in buying on the internet, most people still visit stores and shops for the majority of their purchases. There, at the point of purchase, good POP displays showcase the brand superbly and entice the consumer - because there is no substitute for seeing a product in real, three-dimensional form.

Of course, POP shouldn't necessarily be regarded as a substitute for other forms of advertising. But because it is the final link in the marketing chain, it can act as a reminder to the consumer as well as a sales point, reinforcing and endorsing the brand image that has been built by a variety of exposures across a variety of media.

P\&G believes strongly enough in the power of POS to have created a 15-person FMOT (pronounced 'eff-mott') or First Moment of Truth department at their headquarters, supported by 50 FMOT leaders stationed around the world. They define the first moment of truth as the vital three to seven seconds during which someone notices an item on a store shelf. Despite spending billions on traditional advertising, the consumer-products giant thinks that this instant is one of its most important marketing opportunities. ${ }^{3}$

Unilever are equally keen to achieve optimum product presence at the point of purchase. According to Nick Widdowson, the merchandising manager of Unilever UK Foods, 'We use advanced category management technology to create a bridge between the supplier and retailer. This allows valuable insight into each other's business, so that shelves are carefully planned in line with a particular retailer's sales goals or customer profile. ${ }^{4}$

\section{SO WHERE DO WE GO FROM HERE?}

Marketing, and in particular brand development, is at the same time a complex activity, and very simple one. Complexity is all around us, as shown by some of the examples above. But the key message has to focus on simplicity. It's about persuading 
consumers to buy your product rather than another, when they have a choice. And it's often about paying a little bit more for a benefit that is as much psychological as technological.

Strip away all the jargon so beloved of marketing professionals. The key decisions come when the consumer's purse is open. When the actual product is being taken off the shelf, or bought off the screen, or pushed by a sales person. It must make sense to maximise the brand impact at the moment of brand choice. This fact was validated in July 2006, when the British Market Research Bureau carried out independent research for Kesslers among a nationally representative sample of 500 adults. Their findings are described and analysed in the latest issue of the Kesslers report, entitled 'How consumers think and behave in-store'.

The key benefit of merchandising and display is that it reminds consumers at that vital moment. It has the added benefit of working for the retailer, making their store look better. The growth of retailer power has become so axiomatic that it is easily taken as a truth. So let's use that truth. Instead of worrying about the growth of retailer power, ${ }^{5}$ a better marketing approach is to work closely with the retailer. Investment in their store, in the form of merchandising and display, is a benefit to all: the consumer gets better presentation and clearer choice; the brand gets to influence the consumer; and the retailer gets a better offer in the marketplace.

As branding becomes more complex, and the marketing budget needs to be spread over a wider area, merchandising and display moves into an increasingly high-profile role. It is no longer the preserve of the sales team, or something you 'have to do to keep the retailer happy'. It is a mainstream marketing tool, working in harmony with all other aspects of marketing, and, like all other aspects of marketing, it's not enough by itself. It's a link in the chain. But the moment the consumer makes their final brand purchase holds a pretty important place in that chain. That's why it makes sound sense to maximise the brand effect by maximising brand impact at that first moment of truth-product purchase in store.

Charles Kessler Editorial Board

\section{References and Notes}

(1) http://en.wikipedia.org/wiki/Brand_management.

(2) http://www.chinasprout.com/html/column15.html.

(3) Article from the Wall Street Journal: In a shift, marketers beef up ad spending inside stores. By Emily Nelson and Sara Ellison, Staff Reporters. September 21, 2005; Page A1.

(4) http://www.jda.com/file_bin/casestudies/Enter prise_July2005_Unilever.pdf.

(5) Marketing Magazine September 2006. POPWhere is it going: why is it growing? 